\title{
Un lugar, nuestro lugar. La experiencia de una toma de tierras en Solares de Icho Cruz (Córdoba, Argentina)
}

\author{
Gerardo Avalle ${ }^{1}$, María Mercedes Ferrero², Sergio \\ Fernando Job³ ${ }^{3}$ Sabrina María Villegas Guzmán
}

Fecha de recepción: 20 de septiembre de 2014

Fecha de aprobación: 26 de noviembre de 2014

\begin{abstract}
Resumen
La historia de Solares muestra las tensiones que se producen en la biografía de sus habitantes al momento de tomar posesión de un terreno, ya sea por elección o por expulsión de la gran ciudad, y las contradicciones que emergen al momento de inscribir ese acto dentro de la legalidad o legitimarlo con prácticas de acción directa. Solares es la historia de gentes que transitan el derrotero de cambiar el modo de apropiación del habitar o reproducir la lógica mercantil de fetichizar la tierra. Con un diseño metodológico flexible, nos introducimos en el relato de los otros para encontrar esa trama argumentativa que nos permitió comprender el sentido de "posesionar" un terreno para vivir. Este texto es una exploración de una experiencia semiurbana de toma de tierras en el interior de la provincia de Córdoba, Argentina; iniciamos el artículo introduciendo al lector en la geografía del lugar, para luego cartografiar las historias laborales y culturales de los habitantes. Posteriormente, exponemos las estrategias políticas que se dieron a sí mismos frente a condiciones de vida objetivas y subjetivas que los expulsaban y dejaron sin lugar, a la intemperie, y frente a ello, la apropiación de la legalidad y sus consecuencias al momento de tomar tierras en estado de vacancia.
\end{abstract}

Palabras clave: tierra, posesión, política, ley, habitar.

1 Doctor en Política y Gobierno. Colectivo de Investigación El Llano en Llamas (UCC-UNC), Córdoba, Argentina. avallegera@homail.com.

2 Licenciada en Ciencia Política. Colectivo de Investigación El Llano en Llamas (UCC-UNC). Becaria CONICET. Córdoba, Argentina. ferreromer@hotmail.com.

3 Doctor en Ciencia Política. Colectivo de Investigación El Llano en Llamas (UCCUNC). Córdoba, Argentina. sergioferjob@hotmail.com.

4 Magíster en Antropología. Colectivo de Investigación El Llano en Llamas (UCCUNC). Becaria CONICET. Córdoba, Argentina. sabvillegass@hotmail.com. 


\title{
A place, our place. The experience of land occupations in solares de Icho Cruz (Córdoba, Argentina)
}

\begin{abstract}
The history of Solares shows tensions occurring in the biography of its inhabitants when taking possession of land -either by choice or by expulsion from the big city- and contradictions emerging when registering that act in the legality or legitimizing it with direct actionpractices. Solares is the story of people who change the mode of appropriating or reproducing the commercial logic of fetishizing land. With a flexible design methodology, we get into the story from the others to find that argumentative plot that allowed us to understand the meaning of "possess" a land to live. This paper is an exploration of a semi-urban experience of land misappropriation in the province of Cordoba, Argentina, and began introducing the reader to the geography of the placeand then mapping the business and cultural histories of its inhabitants. Subsequently, we present the political strategies they gave themselves facing objective and subjective conditions expelling them and leaving them without lands and shelter, and appropriation of legality and its consequences when occupying vacant lands.
\end{abstract}

Keywords: land, possession, policy, law, to live

\section{Um lugar, nosso lugar. A experiência de um assentamento de terras nos Solares de Icho Cruz (Córdoba, Argentina)}

\section{Resumo}

A história dos Solares mostra as tensões que ocorrem na biografia de seus habitantes ao momento da posse da terra, seja por eleição ou por expulsão da grande cidade e as contradições que emergem ao momento de inscrever esse ato dentro da legalidade ou, legitimar ele, com práticas de ação direta. Solares é a história de pessoas que transitam o rumo de mudar o modo de apropriação do habitar ou reproduzir a lógica mercantil de fetichização da terra. Com um desenho metodológico flexível, entramos na história dos outros para encontrar essa trama argumentativa que permitiu-nos compreender o sentido de "possessão" um terreno para viver. Este trabalho é uma exploração de uma experiência semiurbana de posse de terras no interior da província de Córdoba, Argentina; inicia-se o artigo introduzindo ao leitor na geografia do lugar, para depois mapear as histórias laborais e culturais dos habitantes. Posteriormente, se apresentam as estratégias políticas que se deram para sim mesmas ante as condições de vida objetivas e subjetivas que os expulsaram e deixaram sem lugar, a intempérie e ante esta realidade, a apropriação da legalidade e suas consequências ao momento da posse da terra em estado de vagância.

Palavras-chave: terra, possessão, política, lei, habitar. 


\section{Introducción}

\section{Algunas pistas para comenzar el análisis. Decisiones teóricas y metodológicas}

La primera sensación que tuvimos al llegar al barrio Solares de Icho Cruz fue que nuestros preconceptos de lo que era una "toma" de tierras no se correspondía con lo que íbamos, poco a poco, descubriendo. El campo y sus características parecían estar diciéndonos que algo "no encajaba" con nuestras prenociones, o bien que la elección del caso para estudiar la problemática que nos habíamos propuesto era parte de un involuntario error de cálculo. Ese "ruido" inicial, que nos continuó acompañando durante buena parte de nuestro trabajo de campo, paulatinamente fue cobrando sentido cuando pudimos comenzar a ponerlo en relación con distintos elementos que atraviesan la vida de nuestros/as entrevistados/as, tanto en el plano estructural como individual.

En este trabajo abordamos la problemática de la tierra y la vivienda, especialmente centrados en los procesos de ocupación o tomas de tierra, llevados a cabo por poblaciones cuya condición común es la no propiedad o posesión de un lugar para vivir. Posicionados desde una perspectiva conceptual y metodológica, principalmente de corte etnográfico, comenzamos a indagar esta problemática y a poner en tensión las diferentes construcciones teóricas al respecto, atendiendo especialmente a la heterogeneidad de historias que uno puede encontrar dentro de un proceso de este tipo, así como también a la diversidad de estrategias -individuales y colectivas- que se dan los pobladores, para llevar adelante una acción como la que aquí analizamos.

En el apartado siguiente describimos, a partir de los registros de campo que hemos realizado, las particularidades del territorio "Solares". El trabajo de campo se extendió durante dos años (2013 y 2014) y se inscribe dentro de una línea de trabajo más amplia que venimos desarrollando desde 2004, referida a las gramáti- 
cas de la conflictividad social y las tensiones con los dispositivos de la gubernamentalidad que se presentan en el escenario localregional ${ }^{5}$. En este artículo, en consecuencia, nuestro interés está puesto en innovar el modo de abordaje de las problemáticas de tierra en la región, que tienden a proporcionar un acercamiento desde variables más estructurales y espaciales, o una perspectiva más propia del urbanismo, por un lado; o miradas que hacen énfasis en las dimensiones psicosociales y culturales de un proceso colectivo, reduciéndolo a un caso único o excepcional, por el otro. Es por ello que nos distanciamos de cualquiera de esos posicionamientos, y apostamos a encontrar en la propia gramática de los conflictos una clave de lectura que nos permita establecer las mediaciones entre lo micro y lo macro social, los procesos identitarios y la construcción de actores colectivos, las estrategias de confrontación y las de disuasión presentes en la cotidianidad de las personas que llevan a cabo una ocupación de tierra.

Hemos construido, en tal sentido, una estrategia metodológica flexible (Soneira, 2007), compuesta por una serie de herramientas que provienen de la etnografía (Guber, 2011), principalmente la Teoría fundamentada y la hermenéutica. Nuestro registro de campo ${ }^{6}$ ha sido una exigencia que nos impusimos, a efectos de poder ir identificando la reconstrucción de conceptos y lecturas que tenemos sobre la temática; la entrevista ${ }^{7}$ ha sido, a su vez, una técnica clave para recuperar los relatos de los pobladores bajo un formato no estructurado, que permitiera generar instancias de encuentro no regladas (Oxman, 1998) y apostar, así,

\footnotetext{
Ver trabajos desarrollados por el Colectivo de Investigación "El Llano en Llamas", en www.llanocordoba.com.ar

6 Cada autor de este texto elaboró sus propios registros de campo durante todo el periodo de trabajo (2013-2014), el que consistía en el registro de todas las actividades realizadas en el campo una vez concluidas, el registro de relatos, conversaciones e impresiones, así como también la recolección de cualquier documento que fuera compartido por parte de los pobladores de la toma.

Hemos realizado 24 entrevistas a diferentes pobladores de la toma. Ellos forman parte de la "Asamblea de Vecinos" de Solares, son dirigentes, asociados, madres, padres, pero lo que los unifica es su pertenencia al territorio.
} 
a la emergencia de nuevas categorías de análisis. Por su parte, la Teoría fundamentada o Grouded theory (Glaser y Strauss, 1967; Soneira, 2007) y la hermenéutica (Ricoeur, 2001) aparecen en este trabajo de manera entrelazada, no sólo como herramientas de análisis sino como una propuesta epistémica de (de)construir la trama narrativa propia y ajena (Avalle y Gallego, 2014). En este sentido, este ejercicio exigió una lectura muy minuciosa de los relatos, para poder ir identificando recurrencias, lugares comunes, sentidos asociados, equivalencias, oposiciones, etc., y de ese modo comenzar a construir las primeras categorías analíticas que nos permitieron no sólo describir un proceso de toma de tierras, sino comprender su impacto político dentro de los procesos organizativos en los sectores populares. Es ahí donde la hermenéutica comienza a jugar y hacer de las palabras no sólo texto sino, como dice Ricoeur (2001), “acción”, convirtiendo al lenguaje en un soporte en el que transitan experiencias, expectativas y horizontes comunes y posibles. Pasado, presente y futuro se presentan, de este modo, en un mismo acto de construcción y proyección.

Conjuntamente, este enfoque epistémico metodológico se corresponde con una adopción de discursos teóricos que entrelazamos, de modo permanente, con el relato de los entrevistados, resultando un tercer discurso, que es el que, a modo de costura, resulta de lo que ellos dicen, lo que nosotros interpretamos y lo que los discursos teóricos ofrecen como herramientas para la conceptualización. Específicamente, en este trabajo aparecen referencias a las posiciones conceptuales de autores posestructuralistas, postsocialistas y del "open marxism" como Derrida, Foucault, Negri, Virno, Agamben, Holloway, entre otros.

A partir de todo este constructo, indagamos sobre el proceso de conformación de una toma de tierra, atendiendo especialmente a la caracterización de sus pobladores, los procesos organizativos, los efectos en las subjetividades y las regulaciones normativas que recaen en el caso. Sostenemos, especialmente, que esta propuesta de análisis nos permitió mostrar el impacto no sólo político y las transformaciones en el escenario regional en lo que 
refiere al tratamiento que hace el Estado respecto de las tomas de tierras, sino especialmente el efecto en la subjetividad, entendida como procesos de subjetivación política, siguiendo a Foucault (1992) y Guattari (2013), respecto del modo y administración del espacio y la vida, atendiendo en ese sentido a las trasformaciones que tienen lugar cuando la ciudad se convierte en un agente expulsivo, o donde la huida se convierte en una estrategia positiva, de fuga de un sistema opresivo, que "disloca" a los sujetos de sus espacios vitales, de sus relaciones y de sus propios recursos de subsistencia.

\section{Solares de Icho Cruz: ¿la excepción a las "tomas" de tierra?}

Para ubicar al lector, este barrio forma parte de la localidad serrana y turística de Villa Río Icho Cruz, ubicada en el extremo sur del departamento de Punilla, y a una distancia de la ciudad de Córdoba, Argentina, de 47 kilómetros. La comuna, devenida en municipio en 2011, cuenta con 2.054 habitantes, de los cuales aproximadamente la mitad habita en Solares de forma permanente. La actividad económica más importante de la región es el turismo, que se activa con fuerza en la temporada estival (entre diciembre y febrero) y se reduce ostensiblemente en el resto del año.

En sus orígenes, Solares fue ocupado por personas provenientes de parajes rurales aledaños que, ante la necesidad de contar con una vivienda más cercana y accesible a los pocos comercios existentes, así como a los servicios de salud, educación, etc., se fueron asentando allí. Ese inicio explica que durante décadas se conservaran entre sus habitantes costumbres y tradiciones más ligadas a lo rural.

De ese Solares hoy poco permanece; con el tiempo se fue transformando hasta convertirse en un barrio muy similar, en su forma, a los que existen en pueblos y ciudades. La parte central posee un trazado cuadrangular al viejo estilo colonial y sobre el 
boulevard principal, se pueden observar -mayoritariamente- viviendas "muy prolijas y ordenadas"8. Algunas son de construcción reciente, mientras que otras dan testimonio de una historia más larga. Solo cuando el boulevard llega a su fin, aquel "orden" se desdibuja. El trazado comienza a ser más irregular, como consecuencia también de las elevaciones del terreno, apareciendo viviendas más precarias y lotes baldíos, todos ellos con un cartel que indica "propiedad privada: prohibido pasar", o bien "propiedad privada: Ley $9.150 " 9$.

En el cambio de la morfología barrial, no sólo influyó el crecimiento natural de su población nativa, sino que a ello se sumó la llegada en los últimos años de personas con trayectorias disímiles, en su mayoría provenientes de la ciudad, que protagonizaron las tomas de lotes y que transformaron con su presencia la geografía del lugar, tanto en el aspecto físico como en el social.

Particularmente sobre este punto, a diferencia de lo que ocurre con las tomas de tierras en las ciudades, en donde con frecuencia se realiza la ocupación de un mismo gran terreno de manera colectiva y en un mismo momento ${ }^{10}$ (Ciuffolini, 2014 y 2007), en Solares el proceso de tomas fue lento, gradual, en terrenos aislados dentro de un mismo barrio preexistente. Su fecha de inicio puede ubicarse allá por el año 2000, cuando un vecino, trabajando para una repartición pública provincial, tuvo acceso a la información de los lotes (situación catastral y de dominio) y decidió compartirla con otros/as vecinos/as (tanto lugareños

Las expresiones que aparecen en el cuerpo del texto entre comillas ("“") corresponden a frases elaboradas por los entrevistados y/o las reflexiones de los/ as autores/as de este artículo en sus diarios de campo. Las siglas "ER" y "EO" refieren al entrevistador y el entrevistado respectivamente, el símbolo (-) representa una interrupción en la alocución del hablante, (...) frases inaudibles, y [...] frase recortada.

Más detalles sobre esta ley se brindan en el tercer apartado.

10 Ver Ciuffolini (2014 y 2007), Stratta (2011), Giaretto (2010), Izaguirre y Aristizábal (1988). 
como ajenos a la comunidad) que tenían necesidad de contar con una vivienda propia.

Esos datos disponibles de los terrenos indicaban que estaban en calidad de "vacantes", esto es, que carecían de un propietario conocido, ya que eran parte de un loteo realizado en las décadas del 40 y 50 del siglo pasado, cuando el valor de mercado de estos territorios era prácticamente nulo. Al parecer, según los relatos, la adquisición de los lotes fue realizada a la distancia por personas que probablemente ni siquiera conocían su ubicación precisa, de allí que nunca se efectuaron las mejoras correspondientes ni se abonaron los impuestos que gravan la propiedad. Este cúmulo de circunstancias los colocó, como ya afirmamos, en una suerte de estado de vacancia: terrenos privados sobre los cuales nunca se ejerció efectivamente el derecho de propiedad.

Con el correr de los años, la rueda siguió girando y las ocupaciones fueron creciendo, hasta alcanzar el número aproximado de 400 lotes. En un principio, la información circulaba de "boca en boca" a través de familiares, amigos y allegados. Luego, la sanción en 2004 de la ley 9.150, que creó un Registro Personal de Poseedores en el ámbito provincial, significó un verdadero impulso, ya que estableció un nuevo marco legal en el cual apoyar y legitimar las tomas que se venían realizando.

El mismo estado de abandono de los lotes explica que los conflictos por la tenencia de la tierra no se plantearan con los dueños de acuerdo "a los papeles", sino con la comuna (luego, intendencia) que hasta ese momento realizaba un uso político de los terrenos (los alambraba para "preservarlos"), generalmente estableciendo un canje a cambio del pago de los impuestos municipales o promesas en tiempos electorales. Por ello, fueron frecuentes los enfrentamientos con la policía local que, abusando de su poder, llevó adelante todo tipo de acciones para impedir los nuevos asentamientos. Estas circunstancias de atropello y amedrentamiento constante por parte de las fuerzas de seguridad, operando bajo las órdenes del poder político comunal, alertaron 
a los vecinos sobre la necesidad de conformar un espacio de organización colectiva, para defender, a partir de una estrategia conjunta, los terrenos. De esta manera, nació la "Asamblea de Poseedores de Solares de Icho Cruz".

\section{Trayectorias diversas que confluyen en un lugar común}

Otro de los aspectos que despertó nuestra atención en Solares era el universo social presente en las tomas. Lejos de presentarse como un todo homogéneo o sencillamente identificable, el grupo de los "poseedores" es altamente heterogéneo. Nuevamente el problema estaba en nuestros preconceptos y en nuestra necesidad fútil de dar con un "patrón" que nos permitiera encasillar a las gentes de un lado o del otro.

Con el ánimo de presentar las trayectorias de nuestros/as entrevistados/as, identificamos distintos aspectos que separamos en dos grupos. Cabe aclarar que tal división sólo obedece a una finalidad analítica, ya que somos conscientes de los profundos lazos de interdependencia existentes entre ellos. Entendemos por trayectorias, en este marco, al recorrido vital que registra un individuo, considerando especialmente sus "condiciones materiales de existencia” (Izaguirre y Aristizábal, 1989).

\section{Aspectos habitacionales y laborales}

Antes de protagonizar las tomas, los/as entrevistados/as, en su mayoría, alquilaban una vivienda o bien gozaban de la posibilidad de continuar viviendo en la casa familiar. En el caso de los primeros, el empobrecimiento paulatino -producto de un costo de vida en constante aumento- los obligó a ir en búsqueda de alquileres cada vez más accesibles, en zonas más alejadas de los centros urbanos, acordes con el descenso de su nivel adquisitivo, hasta que llegó el momento en que ni siquiera esa mínima renta pudo garantizarse. 
La sensación que atravesaba cada vivencia era la de una creciente situación de expulsión dentro de la estructura social, esto es, dejar de percibir una serie de servicios, renunciar a la posibilidad de elegir dónde vivir, verse impelidos a administrar los ingresos de modo tal que sólo podían "pagar un alquiler". Ese esfuerzo permanente por encontrar una solución dentro de la legalidad los fue empujando hacia los márgenes de la ciudad, donde la renta por la vivienda es menor, los servicios básicos no llegan o están con tarifas sociales ${ }^{11}$, etc.; en definitiva, un proceso de tránsito permanente que no permite anclar los cuerpos a ningún territorio.

Nosotros vivíamos en Córdoba, en Nueva Córdoba ${ }^{12}$ primero, después pasamos a barrio Güemes. Siempre trabajando así... en cosas... él trabajaba en un bar, después trabajó en una empresa de limpieza, después en una empresa de seguridad, así. Y trabajábamos los dos. Yo siempre hice muchas artesanías, esas cosas... más trabajo por cuenta propia. Pero igual, nosotros siempre donde estuvimos viviendo en pareja siempre alquilábamos, pagábamos alquiler... [...] y con el tema de los alquileres nos tuvimos que ir yendo como más lejos del centro porque los alquileres en el centro están más caros, así que ahí nos mudamos para la zona sur de la ciudad, nos fuimos para Villa Libertador ${ }^{13}$, que era en ese momento lo más barato en alquileres. (Entrevista personal, mujer, 30 años).

Los que vivían en casas de sus familias corrieron con similar suerte. Las dificultades económicas derivaron con el tiempo en una situación de hacinamiento habitacional, en la que confluían en un mismo espacio varias generaciones de una misma familia.

\footnotetext{
$11 \quad$ Tarifas de servicios públicos subsidiadas por el Estado para sectores desfavorecidos, vulnerables o en emergencia habitacional.

12 Barrio céntrico de la ciudad de Córdoba, de alto poder adquisitivo, con emprendimientos inmobiliarios crecientes, y fuerte revalorización del precio del suelo.

13 Barrio más poblado de la ciudad, que concentra altos niveles de hacinamiento y pobreza.
} 
En ambas realidades, tuvieron la sensación de llegar a un "límite", en el que la falta de opciones los había colocado en una situación "bisagra" y que más abajo (dentro de la escala social) no se podía caer.

Yo estaba viviendo en la casa de mi mamá [...] es una casa que son 2 piezas, y en un momento estaba yo viviendo ahí, pero después como que vino otro hermano mío más, con su familia y ya éramos... después otra hermana más mía, eh... construyó atrás, entonces como que cada vez éramos más [...] y yo dije bueno, como que me fue llevando esa situación sobre todo, viste, como de mucho hacinamiento. (Entrevista personal, mujer, 40 años).

La diversidad de experiencias e inscripciones también se hace presente en el plano laboral. Del trabajo por cuenta propia, tanto artesanal y artístico como en oficios (carpintería, electricidad, etc.), pasando por los empleos en relación de dependencia formales o semiformales (fábricas, empresas de servicios, docencia, coordinación de proyectos sociales, etc.), e informales (limpieza doméstica, cuidado de niños, venta de ropa, etc.), hasta los programas nacionales de asistencia social.

... trabajaba en Prosegur, una empresa grandísima, que tenía todos los beneficios, tenía todo... menos la vivienda que era lo que necesitamos, tenía todo. (Entrevista personal, hombre, 35 años).

$Y$, yo estuve trabajando durante la temporada, y después estoy pegando así como changas, por ejemplo le cuido el niño, o a veces la chica de la prefabricada necesita que le limpie, como que me voy rebuscando [...] pero, tengo, cobro la Asignación ${ }^{14}$, que no es gran cosa pero... el papá de mi hijo me pasa el dinero

14 Asignación Universal por Hijo (AUH), cobertura universal por hijo provista por el Estado nacional para madres/padres desempleados. 
de mi hijo, y bueno, y estas changuitas (Entrevista personal, mujer, 36 años).

Y empecé a trabajar en negro ${ }^{15}$ toda mi vida, y ahora estoy empezando a trabajar en blanco. En blanco ni hablar, entre comillas, claro, porque no tengo recibo de sueldo en ningún lado. Ahora me pidieron de PAMI que haga el... el pedido del monotributo ${ }^{16}$ porque si no, no me van a pagar y bueno, ya lo hice, está en camino. (Entrevista personal, mujer, 32 años).

Como se aprecia en los relatos, la imagen que expresaba el territorio a medida que lo íbamos recorriendo, y nos interiorizábamos en las historias personales, es la de una población caracterizada por la itinerancia, no solo en lo que refiere a la residencia, sino también al tránsito o la movilidad en los puestos o modalidades de trabajo. El empleo registrado y fijo no aparece en la historia de ninguno de los residentes de Solares. El trabajo se naturaliza en el relato como una práctica informal, breve, al que se acude como estrategia de subsistencia, pero que no otorga ninguna garantía ni seguridades. La literatura sobre las transformaciones del mundo del trabajo es bien amplia en lo que refiere a la crisis del salariado (Castels, 2006), la ruptura del imaginario laboral (Svampa, 2000), la estabilidad de los empleos (Gautié, 2004), y la capacidad del mismo como organizador de la vida social (Antunes, 2005; Guadarrama, 2003; Ciuffolini, 2010; Avalle, 2010 ${ }^{10}$. Los mismos señalan las profundas transformaciones que se registraron en el mundo del trabajo latinoamericano a partir de los años 70 y profundizados durante la década del 90. La ausencia de puestos laborales, o su condición de empleos temporales, impactó directamente en la estabilidad ocupacional y en la proyección de los individuos respecto de sus planes de vida. Esa precarización, desempleo y flexibilización del mercado de trabajo trajo como consecuencia un creciente número de población

Trabajo informal, no registrado.

16 Normativa fiscal que regula a los trabajadores independientes. 
que actualmente registra una inscripción informal en el mundo laboral, despojado de las protecciones sociales y resguardos que el empleo registrado otorga.

\section{Aspectos educativos y culturales}

El nivel educativo de quienes protagonizan las tomas es, asimismo, un elemento que merece ser destacado. Los relatos de vida incluyen el tránsito por la educación superior (técnica/artística y universitaria) que en algunos casos pudo ser finalizado, completo o no, lo cual constituye un importante capital social (Bourdieu, 2000). Además de la formación adquirida por medio de la educación formal, otro aspecto que despierta interés en las historias personales es la participación previa en actividades sociales (centros comunitarios, promoción de la salud, radios comunitarias, entre otros) y políticas (militancia en partidos políticos y movimientos sociales). Dichas experiencias contribuyeron a generar una voz $\mathrm{y}$ un criterio propio entre los/as entrevistados/as, ya que, como afirma uno de ellos, "mucho de lo que uno es, obviamente, es por todos los lugares por donde uno ha transitado".

Hice ahí todo el secundario... bueno, después en una época yo estudié agronomía, estudié varios años, pero en realidad llegué hasta tercero (risas) y bueno, ahí también como que me formé mucho, aprendí mucho no solo del tema de la cuestión de la carrera en sí, sino también de participar mucho, ponele... en el Centro de Estudiantes, de haber ido a muchas actividades [...] También mucho de lo que uno es, obviamente, es por todos los lugares por donde uno ha transitado. (Entrevista personal, mujer, 40 años).

El nivel educativo de los/as entrevistadas/os se condice con los gustos y preferencias culturales que aparecen en los relatos. Ambos aspectos parecen encontrar una mejor correspondencia con sectores provenientes de la "clase media" antes que con los sectores populares (Cerrutti y Grimson, 2004; Adamovsky, 2009). Uno de estos elementos es la necesidad de escapar, fugarse, de la 
ciudad y de todos sus atributos negativos -excesivamente poblada, saturada, ruidosa, contaminada-, en búsqueda de la tranquilidad y de una mejor calidad de vida.

En estos casos, participar de las tomas también fue producto de una elección de vida. A la par de estas consideraciones, se deja entrever una crítica a la noción del progreso/desarrollo y a la sociedad de consumo hegemónica, así como un deseo de proyectar la vida más allá del trabajo. El efecto expulsivo del sistema imperante es fuertemente denostado en los relatos, la percepción objetiva de no encontrar lugar en el mundo laboral, en la vida cotidiana, en la ciudad, se funde con la escena de la huida, la necesidad de fugarse de toda esa dinámica que se torna opresiva para la vida ${ }^{17}$; se huye porque son expulsados, pero al mismo tiempo huyen de aquella lógica en la que se ven inmersos los trabajadores precarios, las grandes urbes, la explosión inmobiliaria, etc.

Yo igualmente acá llegué como... huyendo de la ciudad; bueno, siempre fue como mi proyecto irme de Buenos Aires, era terminar de estudiar, recibirme, que mi pareja hiciera lo mismo y bueno, terminamos, huimos. (Entrevista personal, mujer, 27 años).

El repaso por el conjunto de estos aspectos deja al descubierto que entre el par cultura/educación y las condiciones materiales de existencia, ejemplificadas a partir del par habitación/empleo, hay un desanclaje ${ }^{18}$. Si esto es así, ¿corresponde caracterizar a los/as entrevistados/as como "pertenecientes" a la clase media o baja, o es que participan de ambas a la vez?

\footnotetext{
17 Las nociones de "fuga" y "huida" aparecen reiteradamente en los textos de Foucault, Agamben, Rancière, entre otros, como estrategias de resistencias que construyen los sujetos frente a sistema de dominación que, más que oponérsele, lo denuncia y le enfrenta otro modo alternativo de gobierno de los cuerpos.

18 Uno de los primeros teóricos en plantear la noción de "desanclaje" o desconexión ha sido Anthony Giddens, noción que fue retomada por Castels (2006), Fitoussi y Rosanvallon (2004), y cuestionada también por Negri (2013), Gorz (2003) y Virno (2003) como una crítica a la modernidad y a la sociedad posfordista.
} 
En ese supuesto, ¿sigue siendo la clase el marcador social por excelencia? Si tener trabajo, aun en condiciones formales, ya no da la garantía de poder acceder a una vivienda, ni tampoco la educación superior, otrora tan importante en la movilidad social argentina, queda claro que las estrategias disponibles para mejorar las condiciones de vida ya no son suficientes o efectivas, al tiempo que advierten sobre su incapacidad para regular las desigualdades sociales.

El paso de la sociedad industrial, con su correspondiente orden de clases, a una sociedad posindustrial, en la que todo es altamente flexible y móvil, implicó asimismo que se desdibujaran las "pertenencias" sociales construidas sobre las anteriores bases (Offe, 1992; Virno, 2003; Gorz, 1993, 2003; Castels, 2006; Rosanvallón, 2004; Avalle, 2010; Ciuffolini, 2010). Las barreras sociales, antes estables, hoy se vuelven frágiles y etéreas. En este marco, no es casual el efecto de "no pertenencia" que experimentan nuestros/as entrevistados/as, al sentirse que ya no conforman ni la clase media, ni la clase baja, ni ninguna clase. La sensación de no encajar en ninguna de ellas, de haber perdido el lugar en la sociedad, pareciera estar diciéndonos justamente esto: que la clase se torna un concepto de mucha robustez para expresar las desigualdades. Al respecto, diría Holloway (2004) que la clase, más que una mera condición objetiva, refiere a la lucha por abolir esas condiciones, la que le da todo su contenido; en ese sentido, una de las vecinas señala:

Entonces te va excluyendo y de golpe estás excluido de todos lados, y decís, 'pará, a dónde pertenezco', y sí, pertenezco a los que luchan, pertenezco a los sin tierra, y por eso estoy acá. (Entrevista personal, mujer, 40 años).

Tampoco es casual la impresión que tuvimos al iniciar el trabajo de campo, pensando que habíamos "fallado" en la elección del caso. Aquello que se nos presentaba como una "mezcla" poco comprensible de individuos con orígenes y trayectorias de clase diversas, de a poco va cobrando sentido cuando lo pone- 
mos en relación con las distintas transformaciones que operaron en el plano estructural, entre ellas, sobre el mundo del trabajo, esto es, lo que muchos autores han señalado respecto del proceso de desclasificación experimentado a partir de las sucesivas crisis económicas globales iniciadas en los años 70 (Fitoussi y Rosanvallón, 2004), junto con la implementación de políticas de libre mercado y creciente mercantilización de las relaciones sociales (Offe, 1999; Salas, 2000).

\section{Desde la tierra al espacio}

La historia de cualquiera de los habitantes de Solares nos permite ahondar en el concepto de dislocación, entendida como el descentramiento del sujeto, su desconexión y la necesidad de fuga y recuperación (Foucault, 2007; Rancière, 2006). La presión provocada por condiciones de vida precarias no dejó más opción ni elección que la calle como lugar de residencia. Esa condición de sin lugar permite pensar el territorio desde una mirada no solamente espacial sino recuperar u otorgarle todo su valor simbólico. Hablar de tierra no sólo como lugar físico, amplía la mirada a aquellos relatos que hablan de una conexión con el territorio que se habita; y pensar esos lugares como una construcción social recupera esas experiencias de encuentro con los otros y la instancia colectiva de espacios de participación y lucha.

\section{La expulsión y la dislocación}

El proceso de desclasamiento y el desmoronamiento de los imaginarios que sufrieron algunos de los poseedores está vinculado con sujetos sucesivamente dislocados. Por dislocación se intenta hacer patente la separación de elementos distintos que formaban una unidad (sujetos y tierra). Esta separación no señala el quiebre de un elemento, sino la separación de elementos en el lugar donde se articulan (territorio). También ella es producto de un hecho traumático grave (la huida y la expulsión), que será a su vez productora de todo un nuevo modo de estar y muestra 
su faceta más aguda cuando deja a los individuos sin un lugar donde estar, excluyéndolos así del mundo, tanto en sentido físico como social.

Sin embargo, ese proceso de configuración del mundo social, político y cultural, encuentra una primera superficie de constitución, según emerge en las entrevistas, en una materialidad concreta: la tierra. Este es el lugar, esa racionalidad local, desde el cual se van constituyendo subjetividades individuales y colectivas. Es, entonces, en el estar en esa materialidad concreta que comienzan a configurarse las prácticas sociales.

Esta relación que se establece entre tierra-lugar y espacios, y estos locus en los que es posible desarrollar el trabajo, la política y el futuro, van a ir dando por resultante una compleja dinámica de inclusión a partir de la toma, y de exclusión, en la que el mercado, como dispositivo del poder, funciona como el lugar privilegiado de constitución de las posesiones y desposesiones, no sólo de quienes tienen tierra-lugar y quienes no, sino entre quienes tienen posibilidad de existencia y quienes son condenados a "vivir a la intemperie".

El hecho de sacarte de un lugar, en donde estabas, que seguramente alquilabas, no podés alquilar más, te vas, moverte, sin nada, a la intemperie, con chicos. Sabés lo que es empezar a vivir así, en esas condiciones... sin baño, sin cocina, entonces en ese marco vos no entendés, no comprendés la cuestión esta de qué son estos tipos, no tienen sangre, son todos iguales. (Entrevista personal, hombre, 50 años).

Estar a la intemperie, es no tener un refugio, un lugar donde ir. Es observar cómo las instituciones estatales se suman a las dinámicas propias del mercado, para continuar y profundizar ese proceso de dislocación. Estar excluido, en la concepción de los entrevistados, es justamente no tener lugar donde estar. Sin lugar no hay espacio, y sin éste no hay posibilidad ni de trabajo, ni de política, ni de futuro. El recorrido que en un primer momento se presentó como un fuerte proceso de desclasamiento, en la 
escucha atenta empieza a incorporar conceptos que permiten mostrarlo en todas sus dramáticas dimensiones.

Como el Estado en cierta forma no se hace cargo, el sistema no se hace cargo, nosotros somos excluidos del sistema. Yo intenté, o sea, nosotros con mi familia intentamos acceder a una vivienda y pagarla [...] viste cuando vos decís 'Dios los cría, ellos se juntan y el viento los amontona', y bueno, nos amontonó en este caso acá... y yo es cierto, yo me sentí excluida de un montón de... del sistema... nos pateaba para afuera, no entrábamos ni en la clase media, ni en la media baja, ni en ninguna clase, no existíamos. (Entrevista personal, mujer, 42 años).

El desarraigo produce tal dislocamiento que la identidad de los sujetos se ve fuertemente impactada, generando la imposibilidad de pensarse como parte, no ya del sistema o del Estado, sino de una clase social determinada. Ser excluido, además de lo ya dicho, implica no existir, no tener dónde ir. Empiezan a levantarse por doquier barreras de invisibilidad, que van reforzando la idea de la inexistencia, de la no escucha, del aislamiento y la soledad. Ello advierte sobre la etapa actual del mercado y el Estado, en la que no se piensa ni proyecta frente a ciudadanos ni sujetos, sino a cuerpos y cosas que deben ser administradas en-sobre el territorio, y a partir de allí en los espacios donde las prácticas y los relatos se construyen.

Frente a todo este proceso de dislocamiento, los sujetos esgrimen diversas respuestas. En general, éstas se concentran en tres principales: la huida, el asentamiento en una tierra-lugar $\mathrm{y}$, por último, la constitución de espacios donde sentir amparo. Algunas veces se observa una de estas respuestas sola, y en otras se presentan como un proceso que se prolonga: huida de la ciudad o de la situación anterior; (continuado en) la toma de un terreno para (re)construir la vida desde ese nuevo lugar; y posteriormente, desde el asentamiento, desde el estar presente en la materialidad concreta de la tierra-lugar, la lenta edificación de 
espacios laborales, culturales y políticos a partir de los cuales se reconstruyen como individuos.

\section{Huir y organizar}

La idea de la huida se repite a lo largo de numerosas entrevistas, y se comprende aquí que no es casualidad. Frente a un mercado y un Estado gubernamentalizado, que presenta como práctica preferencial de ejercicio de su poder, el ordenar cuerpos y cosas en-sobre el territorio, recurrir a la huida se presenta como un modo efectivo de disidencia, construyendo sujetos inaprehensibles y escurridizos a las dinámicas propias de este poder regulador. Las ciudades, con su cuadrícula ordenada y su rearticulación espacial, serán el territorio predilecto de este nuevo poder regulatorio. Huir de la ciudad es mucho más que escapar de un medio ambiente determinado, es la posibilidad de desarrollar prácticas y lógicas diversas a las construidas desde el poder. La dislocación constante en que deben desarrollarse los sujetos actuales, y luego del nuevo proceso de desanclaje que sufren al tener que romper los lazos que los amarraban a un territorio determinado en las ciudades, encuentra cierto refugio o amparo (dirá esta entrevistada) en el asentamiento en la tierra-lugar.

Digamos que a nosotros nos recibió la tierra, nosotros sentimos que nos recibió, por eso que le agradecimos en el momento que pisamos la tierra, y yo creo que el lugar te recibe o te expulsa [...] Sentir que el lugar te corresponde y vos también, que no viniste a invadir sino a adaptarte, a respetarlo [...] es mágico, eso tiene como magia el valor de la tierra (solloza) tiene el valor del espíritu de la tierra, y yo creo que el espiritu de la tierra ampara a todos sus hijos, que no quede ninguno desamparado, y siento que eso representa ese pedazo de tierra para nosotros (solloza) y por eso creo que es auténtico, que es legítimo. No sé, vamos a discutir si es legal o no, pero que es legítimo es legítimo, yo lo siento así, [...] tal vez, hoy estemos recuperando algo que ya era nuestro, en 
otro tiempo y en otro espacio que era nuestro, y bueno, que tiene que ver con esto, con luchar por los derechos de los que fueron expulsados, tal vez en otro tiempo. (Entrevista personal, mujer, 42 años).

Hay en ese proceso de re-arraigamiento una búsqueda por nuevas y alternativas formas de vivir, que excede la situación particular e inmediata de quien decide "volver a la tierra". Lo que se observa a lo largo de las entrevistas es un complejo tejido témporo-espacial, que encuentra condensación en-sobre la tierralugar. Se trata de sujetos sucesivamente dislocados, que encuentran obturada la posibilidad de pensar(se) en continuidad histórica. Sin embargo, el asentamiento en una tierra-lugar les permite la expansión de la dimensión presente, y desde allí la reconstrucción y reflexión de un pasado (del cual huyen), y la recuperación desde-en lo colectivo, en la Asamblea, de la proyección y el futuro. Empieza a observarse la emergencia de nuevos sujetos situados histórica y territorialmente.

El ámbito en-desde en que se despliegan las prácticas sociales, culturales y políticas, adquirirá en el relato de los/as entrevistados/as la nominación de un espacio concreto, la Asamblea. El mismo será el locus donde comenzará un proceso de reconocimiento y construcción subjetiva, que habilitará una instancia en la que el hacer, el trabajo, se vuelve articulador y disparador de nuevas prácticas políticas, y desde-junto a las mismas, la posibilidad de proyección de algún futuro posible.

Hay poseedores más antiguos que van a la Asamblea en función de que tienen un problema, una dificultad, una amenaza, o sea, la reconocen a la Asamblea, no van a la Comuna, van a la Asamblea, ponele, si tienen un problema de agua, de luz, entre otros vecinos, qué se yo, van al espacio de la Asamblea y se sienten parte y se reconocen, pero la participación esta de tomar parte en la Asamblea, de tomar decisiones, no es así, digamos, por eso digo, es como... no es tal, y no van a todas la reuniones, eh, pero sí se sienten parte, sí están, nosotros 
los reconocemos y ellos nos reconocen como parte. (Entrevista personal, mujer, 33 años).

Sin embargo, lo que muestran los relatos de los/as entrevistados/as es que las categorías que van emergiendo, si bien representan momentos diversos en la constitución subjetiva, tienen entre sí una fuerte co-implicancia, en la cual la tierra-lugar no puede pensarse de manera escindida de los diversos espacios (lugar de la práctica política y el encuentro con el otro) que van irguiéndose sobre el soporte material del lugar, donde lo político y lo territorial se van confundiendo una y otra vez, mostrando que una modificación en la estrategia de intervención y lugares de acción implica también romper con los límites territoriales propios.

Yo creo que la discusión que se plantea es que bueno, nuestra pelea es política. Nosotros necesitamos insertarnos en espacios más políticos, y sobre todo la definición de participar en estos espacios fue... por la necesidad concreta de estar más acompañados, porque realmente, nosotros, llegó un momento de... de conflicto donde sentimos que era necesario abrirnos a otros espacios, salir de las puertas de Icho Cruz, y dar a conocer nuestra situación en la provincia. (Entrevista personal, mujer, 27 años).

En el encuentro con los otros y la lucha posterior, la experiencia vital colectiva se irá reconstruyendo a partir de nuevas lógicas y prácticas. Habrá en estos nuevos modos dos prácticas que emergen insistentemente y que, si bien concomitantes, como dos caras del mismo proceso, responden a diversos frentes de batalla. Estas dinámicas serán la recuperación y la disputa.

La noción de "recuperación" encuentra como superficie de constitución a lugares concretos, pero que inmediatamente son entendidos como espacios, como lugares donde se libra una lucha política. La recuperación, en las entrevistas, se presenta como una lucha frente al afuera, frente a todo aquello que les ha sido arrebatado. La toma de la tierra, de una plaza, de un galpón para la cooperativa, o de los "papeles" y el espacio legal, no es entendido, 
en la lógica de los/as entrevistados/as, como un avance o una nueva situación, sino como una recuperación de alguna situación anterior, no siempre históricamente determinada o determinable, pero sí existente a modo de falta actual. Hablar de recuperación implica hablar de falta, de algo despojado en algún momento.

Recuperar la cooperativa de acá también, que era un cooperativa que en términos de papeles, y a nivel legal había quedado así como abandonada y esto se empezó a recuperar y se puso en regla, y se reabrió una sede que estuvo cerrada durante cinco años... este... que bueno, que yo creo que más allá de los logros y de por ahí, lo que se hizo en concreto y lo que no... todo eso fue demostrando que bueno, esta gente viene a laburar por el barrio, a mejorar las cosas, por hacer, digo, a recuperar espacios que estaban muertos. (Entrevista personal, mujer, 27 años).

La otra dinámica identificada es la disputa. Esta no sucede hacia "un afuera" del espacio, sino que la superficie de constitución es el propio espacio asambleario u organizativo. La disputa sí habla de una situación nueva que debe construirse, que va buscando sendas alternativas que no se erigen pacíficamente, sino en tensión entre experiencias, modos de estar, e incluso entre géneros. La disputa es el nombre que toma la tensión resultante del encuentro entre distintos que intentan hacer de lo disperso y lo diverso un nuevo espacio comunitario.

\section{Entre la posibilidad y el límite: la legalidad en la lucha}

Como narramos, durante el recorrido por el barrio Solares resultó llamativa la referencia a la ley $\mathrm{N}^{\circ}$ 9.150, en carteles confeccionados a mano, pintados de modo impreciso, colgando sobre alambrados o plantados en medio de los lotes. ¿Imágenes? Todos ellos cumplían, a nuestro parecer, una función clara de advertencia respecto de lo que ocurría en esos terrenos, dado que no 
es habitual encontrarnos con esas identificaciones de manera tan concentrada. Las charlas posteriores con los/as vecinos/as del barrio nos aclaró el panorama: tal como ellos lo expresan, la ley forma parte del relato de la posesión y la acción de "posesionar", una estrategia de inscripción en lo "legal".

\section{Una posibilidad para entrarle a la ley}

A lo largo de las entrevistas, los/as poseedores/as construyen un relato sobre la legalidad asociado a sus trayectorias de vida y recorridos de clase. El marco legal de la Ley Provincial $\mathrm{N}^{\circ} 9.150^{19}$ aparece como una grieta, una inflexión en el sistema jurídico-mercantil, que habilita la posibilidad de accionar un modo otro de acceso y tenencia de la tierra, un acceso inserto y normado por la ley, pero instituido desde los márgenes del sistema mercantil. La estrategia legal, desarrollada desde el proceso organizativo de la Asamblea en torno a ese instrumento, constituye, al decir de los/as entrevistados/as, una de las herramientas más valiosas de aquel espacio.

19 Durante los últimos años, una serie de normativas dictadas en la provincia dieron cuenta de la existencia de cierta preocupación alrededor de la irregularidad de los relevamientos catastrales existentes -con el consecuente desorden registral que ello conlleva-y un interés por regularizar dichas situaciones. Un ejemplo de ello lo constituyen las leyes $\mathrm{N}^{\circ} 8.884$ del año 2000, la ley $\mathrm{N}^{\circ} 9.100$ de 2003 y la nueva ley de saneamiento de títulos, $\mathrm{N}^{\circ} 9.150$. Esta norma, que continúa vigente a la fecha, crea un Registro Personal de Poseedores, en el cual todas las personas pueden declarar su posesión sobre inmuebles rurales, urbanos y semirurales. Una vez cumplido el procedimiento que la ley establece a los fines de la inscripción, esta tiene por objetivo regularizar definitivamente la tenencia de los inmuebles declarados. Sin embargo, el Registro de Poseedores y la Unidad Ejecutora de Saneamiento de Títulos lejos están de dar una respuesta integral a la problemática social que subyace a los conflictos relacionados a la tenencia de tierra en la provincia. De esta forma, la Unidad Ejecutora, dado su carácter preventivo -destinado a resolver trámites administrativos y, en algunos casos, a brindar asesoramiento técnico- no resulta ser una herramienta eficaz para modificar la situación objetiva en la que se encuentran los poseedores; de hecho, en los relatos aparece que todos tienen el "trámite iniciado", pero en ningún caso se avanzó en el registro dominial. Incluso señalan que la administración ha cambiado el procedimiento: ya no entregan los comprobantes de trámite y es más frecuente el rechazo de las pruebas que son presentadas para atestiguar posesión y residencia en el terreno. 
De igual modo, reconocen a este particular uso del derecho como una novedad en el marco de las tradiciones y experiencias de lucha por el acceso a la tierra por ellos/as conocidas. Ese aprendizaje y utilización de la herramienta legal va a extenderse luego hacia otros ámbitos del sistema normativo, para interesarse no solamente por el Código Civil y las leyes que regulan la tenencia de la tierra, sino también por ciertos elementos de la legislación penal y de las ordenanzas comunales/municipales respecto del acceso a servicios básicos.

Nosotros somos la única organización en Córdoba que no ha tenido que negociar un terreno con nadie, porque lo hacemos tal cual lo dice el Código Civil, punto y coma, lo hacemos como lo dice el Código Penal, como lo dice la 9.150 ¡no nos apartamos de eso! (Entrevista personal, hombre, 50 años).

\section{La ley como necesidad: reaccionar, defendernos, aprender, armar una estrategia}

El lenguaje de lo legal está presente en las entrevistas y ocupa gran parte de los debates y el trabajo asambleario, marcando una clara impronta en el accionar de los/as poseedores/as, que intenta mostrarse inserta en la legalidad. Los/as entrevistados/as afirman que aquel instrumento que hoy caracteriza a la Asamblea de Poseedores de Solares de Icho Cruz fue construido y diagramado a modo de reacción ante el asedio constante de las fuerzas de seguridad provinciales, de la jefatura comunal del pueblo y los mercaderes de la tierra. El enfrentamiento con la policía, ya sea verbal o físico, aparece -al igual que en gran parte de los procesos de lucha por el acceso a derechos- como la primera forma de "encuentro", de relaciones de fuerza, como señala Marín (2009), con el Estado en las tomas de tierra y también con el mundo de la ley. Las patrullas, el vandalismo y la arbitrariedad policial instituyen una alarma que vulnera la espacialidad cotidiana de los / as poseedores/as y llama la atención acerca de la necesidad de articular formas de defenderse individual y colectivamente. 
Al principio, cuando se empezaron a tomar los primeros terrenos, bueno, esta gente que estaba organizada en el negocio de los terrenos hizo las primeras represalias, las primeras reacciones, que fueron como bueno... ir y sacar esa gente, meterla presa, pintarle los dedos, porque en ese momento, digamos, no se tenía la conciencia que se tiene hoy de que no es un delito, sino que es un acto civil la posesión, que estamos amparados por una ley, entonces hubo como mucha represalia y todo eso quedó, fue quedando, ¿no? (Entrevista personal, mujer, 42 años).

Como indican los/as entrevistados/as, la criminalización del acto posesorio y el amedrentamiento por parte de los actores de poder que lucran con las tierras en la zona del Valle de Punilla, se encuentran en la base y el punto de origen del desarrollo de una estrategia para "ampararse" legalmente. El conocimiento de las leyes se presenta como posibilidad frente a la necesidad de la autodefensa. Desarrollar argumentos técnicos e incorporar el lenguaje jurídico a la discursividad de la lucha se transforman en una tarea principal de la Asamblea, y en una línea de acción y un modo de presentarse frente a los interlocutores estatales y no estatales. El saber legal y la difusión de las "respuestas" que hay que dar ante las amenazas de desalojo o judicialización aparecen, en el registro de los/as entrevistados/as, como la principal fortaleza de la organización, inclusive cuando aquel primer momento de riesgo de enfrentamiento con las fuerzas de seguridad ya no se presente como realidad cotidiana.

En el punto de partida del proceso se encuentra la disputa por el reconocimiento de la lucha como conjunto de acciones insertas en la legalidad, dirigidas a satisfacer necesidades consagradas como derechos (derecho a la tierra, derecho a la vivienda, etc.) en los pactos internacionales, la Constitución Nacional y leyes inferiores; y de quienes toman tierras como poseedores legales en el marco de la ley 9.150. La disputa es ser encuadrados/as dentro de una categoría jurídica del Código Civil (la "posesión") que, de cierta manera, legaliza una forma de ocupación, uso y adqui- 
sición de la tierra, para evitar así ser condenados por el delito de "usurpación", indicado en el Código Penal.

Son esas "estrategias" que despliegan frente a la legislación civil y la penal para legitimarse desde una discursividad de lo legal, las que requieren de la reapropiación de los saberes técnicos del derecho por parte de la Asamblea y de la búsqueda de asesoramiento sobre el área.

El saber legal y el lenguaje técnico se constituyen también como una marca de posición social, ya que el conocimiento técnico-científico se erige como capital de determinado sector social. En el relato de los/as entrevistados/as se construye una trama argumentativa que vincula la cuestión de la ley y el saber, para sostener que se es un ciudadano con conocimiento de sus derechos y que no se está cometiendo un delito: "no soy usurpador, porque conozco la ley y tomo posesión de la tierra acorde a ella". Es así como la disputa por el reconocimiento legal se conjuga y se hace inescindible de la disputa por el lugar que se ocupa/se pretende ocupar en la estructura y la organización de la sociedad.

\section{Sin la ley me siento en banda}

La experiencia de habitar el territorio constituye un modo de estar específico que los habitantes de Solares permanentemente reivindican. En sus relatos, sorprende el ida y vuelta que establecen entre una lógica racional y estratégica y otra que se aproxima a una racionalidad local. La primera es la que hemos abordado en el apartado anterior, ese modo argumentativo que inscribe todo accionar en el marco del "deber ser"; la otra, más personal, colectiva y comunitaria, expresa esa conexión del lugar con la estructura de sentimientos de cada poseedor, una mística en torno a la tierra que los liga más allá de la razón.

En este sentido, aparece en las entrevistas una preocupación fundamental por diferenciar la acción legal de la acción delictiva y, sobre todo, de legitimar la acción propia a partir de 
(de)mostrarla inserta en el marco de la legalidad. Así, a diferencia de los sectores populares, para quienes siempre ha estado limitada la posibilidad de acceder a la tierra (y los recursos en general) dentro del marco del sistema jurídico-mercantil, y ante quienes la realidad se presenta como necesidad de sobrevivencia sin importar (en principio) la condición legal/ilegal de las acciones destinadas a ello, los/as entrevistados/as manifiestan como inquietud fundamental el precisar y preservar ciertas "formas" del hacer y del decir, correspondientes con la ley y con el "deber ser" en general.

Hay una lógica moral y de lo correcto, propia de los sectores medios y altos de la sociedad, que va más allá de lo estricta y puntualmente estipulado en la ley, permeando los discursos de los/as entrevistados/as en lo que hace a sus estructuras de percibir, sentir y estar en la lucha. Es en ese intersticio entre el deber ser de la lógica racional-estratégica y el estar que imprime la racionalidad local, que aparece un modo propio de nombrarse y de ser: el poseedor. Sujeto que instituye un acto propio, "posesionar" y presente, "posesionando".

"Sentirse en banda", en palabras de una de las entrevistadas, se relaciona con la inseguridad que produce el desajuste entre la anterior situación material y de clase -real o imaginaria- y la nueva condición de necesidades con limitadas posibilidades de satisfacerlas. La tranquilidad que los/as poseedores/as anhelan en relación a un tiempo pasado que se menciona en el relato, en el cual la situación laboral, habitacional y, en general, la situación de vida fue distinta (con mayores seguridades y garantías), se ve vulnerada por la realidad actual. Esa situación de incertidumbre, producto del descenso en la escala social, es la que (re)produce el esfuerzo constante por alcanzar aquellas pequeñas seguridades.

Lo llamativo en esto es que no necesariamente tuvieron una mejor condición en el pasado. Como se trabajó en el primer apartado, las experiencias e historias de vida de los pobladores de Solares es bien heterogénea: algunos provenientes de sectores 
populares, poblaciones rurales, periferias de las grandes urbes; otros, como una elección lejos de la vida citadina, o huyendo de la expulsión provocada por la ciudad, que permanentemente los empujaba a las periferias. Esas "seguridades" que se procuran alcanzar se asocian a lo que Bayón (2003) señaló como "la erosión de las certezas previas" que otorgaba el mundo salarial y el empleo estable.

Ante la incertidumbre de la nueva situación material, aparece el miedo como sensación que trasciende y estructura a la persona: miedo a no saber, miedo a estar delinquiendo, miedo a relacionarse con delincuentes. A fin de cuentas, se trata del miedo que emerge de la no coincidencia, del desajuste de temporalidades entre la posición de clase y aquellas "disposiciones y estructuras estructurantes", parafraseando a Bourdieu y Wacquant (1995), que los/as entrevistados/as poseen en el deber, el hacer y el sentir.

En dicho marco, el primer paso para conquistar la tranquilidad se presenta en relación a hacer posible la autopercepción de que lo que se está accionando "está bien", "es legal", y es allí donde aparece la mención de la "seguridad de los papeles", los trámites, una tranquilidad burocratizada que solo existe para aquella clase social para la cual toda su trayectoria de vida ha estado intervenida por "los papeles" y estructuras burocráticas de los más variados tipos.

Así, dicho "estar bien" se justifica discursivamente desde la legalidad, desde la existencia de un procedimiento, de una forma, y no desde la legitimación de la acción a partir de la situación objetiva de la necesidad actual que se atraviesa.

La propia convicción que se logra en el justificativo "es correcto y me da tranquilidad porque es en el marco de la ley", entra en contradicción con una realidad social que demuestra que la ley está lejos de ser inviolable y constituirse en criterio máximo ordenador de la dinámica social. Al contrario, la cotidianidad que atraviesan los poseedores, tanto con sus vecinos/as como con los 
sectores del poder local, se ve afectada por procesos de estigmatización, criminalización y discriminación que, lejos de legitimar la lucha, por estar enmarcada en el procedimiento estipulado por la ley 9.150, los califica de "vagos", "delincuentes", "pobres".

\section{La tensión irreductible legalidad-lucha}

Al comienzo del presente apartado introducíamos la manera en que los/as entrevistados/as articulaban un discurso de la legalidad como necesidad frente al asedio del poder y el amedrentamiento policial. Hacia el final del mismo, pudimos vislumbrar cada vez más cómo aquella estrategia legal comienza a presentarse como ineficiente, insuficiente y hasta perjudicial a los objetivos de la lucha. Por una parte, los/as entrevistados/ as entrevén la existencia de otros sistemas de legitimación, que adquieren relevancia por sobre el legal. Por otra parte, algunos/ as entrevistados/as (no todos/as ni la mayoría) comienzan a advertir el riesgo que el legalismo implica como característica del proceso organizativo por el acceso a la tierra. Respondiendo esto último no solo a que la ley escrita es, la mayor parte de las veces, letra muerta, sino también a que la propiedad privada de la tierra es un principio inclaudicable del sistema normativo como totalidad ${ }^{20}$. Aquello que aparecía como posibilidad, como fisura, a final de cuentas puede no significar más que algunos "espejitos de colores", como dice la popular metáfora colonial.

Vamos a cortar la ruta. Ahi nos van a escuchar, pero por qué tenemos que llegar a eso si hemos hecho todo lo que dice la ley. (Entrevista personal, hombre, 50 años).

A la lectura sobre la ineficacia de la estrategia legal como forma de acceso a derechos, se suma la lectura acerca de otras

20 Esta consecuencia es advertida fuertemente por Ciuffolini (2007) cuando analiza las luchas urbanas por la tierra, especialmente sobre los riesgos de burocratización a los que se ven expuestas las organizaciones sociales cuando entran en relación con la estatalidad. 
metodologías y modos de acceso y de lucha. El corte de ruta, las conexiones ilegales, se construyen como posibilidad en un marco de necesidades materiales reales y concretas, pero, sin embargo, los/as entrevistados/as siguen preguntándose "por qué tenemos que llegar a esto", qué situaciones fueron sucediéndose para desembocar en esas otras herramientas en paralelo o al margen de la ley (porque inclusive el entrevistado parece ubicar a los métodos de lucha como ajenos a los derechos instituidos). Es en esa tensión entre la legalidad y la lucha en que aparecen los límites del legalismo que, por mantener esa línea de acción, construye un discurso que termina reificando y consagrando la propiedad privada de la tierra.

En estos casos, o sea, el lote se le deja a la persona, no es que también vamos a estar luchando contra (-) o sea, contra alguien que realmente es el dueño del lote. (Entrevista personal, hombre, 34 años).

Y el lote que tiene dueño con escritura no sé... digo, podría cuestionarse, pero no se cuestiona. Nosotros, si hay alguien que compró, en un remate, en lo que sea, es su titular dominial y tiene derechos. (Entrevista personal, mujer, 34 años).

En este sentido, es importante identificar el lugar que ocupa la figura del "dueño" o el "heredero" en los discursos de los/ as poseedores/as. Las entrevistas introducen dicha imagen para justificar el carácter legal de lo que se está haciendo. Sin embargo, terminan, por ello mismo, encasillando la lucha en aquella pequeña fisura, "una puertita", que el instrumento legal representa. En vez de usar la grieta para hacer estallar esa estructura y proponer una forma de lucha que cuestione el orden de la propiedad, logrando desde allí la satisfacción de la necesidad material, construyen una barrera que contiene la disputa al colocarla entre los barrotes del sistema jurídico-mercantil.

El efecto negativo que tiene la intromisión del lenguaje jurídico en el relato de los poseedores es el de que el "dueño" o el "heredero" adquieren superioridad de derechos frente a quien nece- 
sita la tierra; el "papel", la "titularidad", los ubican por encima de la toma de tierras y de toda la estrategia desarrollada en torno a ella. La única posibilidad que se conjetura para la continuidad de la tenencia de la tierra en la que se vive es la mercantilización del acceso, que termina teniendo también para los/as entrevistados/as la mayor fuerza legitimatoria.

Finalmente, el ánimo de lucro impera y se vuelve necesario pagar para adquirir derechos. Ese es el marco que propone el sistema normativo y el riesgo al que se ven expuestos desde el espacio organizativo de la toma. Es esa la tensión no resuelta en el marco de la lucha de la Asamblea de Poseedores. El esfuerzo por mantenerse y mostrarse insertos/as en la legalidad obtura otras posibilidades de cuestionamiento del orden social. Aquello que se percibe colectivamente como fortaleza requiere ser abordado también como debilidad, a modo de (re)creación de la disputa y de extensión del campo de lo posible en relación a la forma de vida que se desea y que pretende construirse.

\section{Algunas reflexiones finales}

Quienes escribimos este artículo podríamos liberar nuestra imaginación de las ataduras que la ciudad y su locura nos impone y habilitar e invitar, a este texto y al lector, a rememorar la historia de José Arcadio Buendía, el célebre personaje que funda el poblado de Macondo, un territorio acechado por miles de tempestades que albergó a numerosas generaciones de alquimistas, trabajadores, trashumantes, exploradores, gentes que huían, se refugiaban y construían un modo de habitar la tierra.

La experiencia de transitar Solares, conocer a sus pobladores, compartir sus vivencias, sus historias, sus memorias, fue haciendo que esa "magia" que proyectamos al huir de la ciudad fuera ganando realismo, y las miserias y virtudes formaran parte de la alquimia que se estaba construyendo en ese territorio. Nuestros primeros párrafos aquí -ni mencionar nuestros registros de campo- advertían sobre una sensación de desasosiego que nos 
inundaba al comenzar a caminar un territorio que distaba de la geografía de las metrópolis.

Culmina en este texto la reflexión sobre una historia que tiene todos los componentes de la vida misma: magia, realismo, (des) amores, dolores, alegrías, luchas. La población de Solares tiene una trayectoria laboral, cultural, familiar y de existencia que resulta complicado encasillarla en las clásicas categorías de estratificación social. Diríamos, en este sentido, que los estratos son expulsivos para ellos si queremos que todos entren dentro de un mismo perfil.

Los y las de Solares son personas que han visto descender de modo abrupto sus condiciones materiales de vida. Son también personas que se vieron expuestas al proceso mercantilizador de la tierra, de lo urbano y de la vida, y se enfrentaron a un proceso creciente de expulsión y de no lugar. No solo no hay estrato que los contenga, tampoco hay tierra que los albergue. Así es que comienza una huida como estrategia de supervivencia y como elección, en que hallar un lugar se convirtió en esa tierra de vacancia que los contuvo.

La huida se combinó con la construcción de espacios de encuentro de gentes, lugares desde donde hablar y lugares desde donde poder decir, y en ese espacio se habilitó la disputa entre los modos de estar y sentir, las formas entre las cuales optar para construir una vida juntos. Asentarse en Solares empezó, entonces, a ser ese lugar donde vuelven a fundirse dos elementos, el cuerpo y la tierra.

Lo que hace de esa huida un acto político en sí mismo es la conjunción con otro verbo apropiado de la misma legalidad, el de "posesionar". La sanción de la ley de regularización de tierras provinciales refuerza la normativa existente en el país sobre actos posesorios, y son las gentes de Solares quienes encuentran en ese instrumento un intersticio, "una puertita", para inscribir su modo de vida dentro de la legalidad. 
En ese espacio colectivo de formación y autodefensa, el uso y manejo del derecho se tornó una de sus principales herramientas de lucha frente al asedio policial, político e inmobiliario. Sin embargo, ese "amparo" legal frente a los otros no se convierte al mismo tiempo en un "albergue" desde donde poder disputar justamente el tema central de su huida y elección, el modo de apropiación y uso de la tierra. El problema de la legalidad, o tanta legalidad, es que termina fraccionando la práctica posesoria a la lógica económica de mercantilización de la tierra. De este modo, la asamblea se ve inmersa en una tensión irreductible, pero no definitiva, de optar por reproducir la pétrea dinámica de la propiedad de la tierra, o intentar, desde la misma legalidad, un uso alternativo del derecho y reclamar la función social de la misma.

Esa tensión está presente en cada práctica, la necesidad de "saber" de derecho embarga sus relatos, los conduce hacia el campo de los procedimientos, hacia una racionalidad estratégica que corre el riesgo de agobiarse y empantanarse entre expedientes sin fin; pero también aparece, en ese campo de disputas que implica la construcción de un espacio donde tenga lugar la vida juntos, el deseo de ser legalmente irracionales y afirmarse en la tierra desde un lugar-otro que es el de habitarla no solo desde la necesidad, sino desde un imaginario colectivo, tan mágico como real, que es el de romper con la especulación y el negocio de la tierra, y construir una forma otra de apropiación del habitar.

Será la relación que los propios proyectos gubernamentales establecen, entre no ser, no estar, no tener; entre tierra-lugar y espacio; entre la posibilidad de constituirse como sujetos que superen la condición de nuda vida propia de los cuerpos; entre trabajo, existencia y política, lo que hará que la búsqueda de comprensión y superación de la dislocación brutal a que fueron sometidos, implique necesariamente la disidencia y resistencia a un sistema en el que la simple búsqueda de un lugar vital signifique una estrecha y necesaria relación entre política y vida, en la medida en que se niegue a ser población destinada al sin lugar y sin existencia. 


\section{Referencias}

Adamovsky, E. (2009). Historia de la clase media argentina. Buenos Aires: Planeta.

Antunes, R. (2005). Los sentidos del trabajo. Buenos Aires: Herramienta.

Avalle, G., y Gallego, A. (2014). Una estrategia metodológica posible: el discurso de los sujetos. En A. Núñez, M.A. Ciuffolini, et al. Tiempos itinerantes. Apropiación y expropiación de territorialidades sociales en ciudades argentinas. (pp. 31-60). Mar del Plata: Eudem.

Avalle, G. (2010). Las luchas del trabajo: sentidos y acciones de docentes, meretrices y piqueteros en Córdoba. Tesis de Maestría en Sociología. Serie Thesys. Córdoba: EDUCC.

Bayón, M. (2003). La erosión de las certezas previas. En Perfiles Latinoamericanos, 22. México: FLACSO.

Bourdieu, P. (2000). Las formas del capital. Capital económico, capital cultural y capital social. En: Poder, derecho y clases sociales. Bilbao: Desclée de Brouwer.

Bourdieu, P. y Wacquant, L. (1995). Respuestas por una antropología reflexiva. México: Editorial Grijalbo, 63-99.

Castel, R. (2006). La metamorfosis de la cuestión social. Una crónica del salariado. Buenos Aires: Paidós.

Cerrutti, M. y Grimson, A. (2004). Buenos Aires, neoliberalismo y después. Cambios socioeconómicos y respuestas populares. Buenos Aires: Cuadernos del IDES.

Ciuffolini, M.A. (2007). Luchas urbanas por la tierra. En Anuario IX del Centro de Investigaciones Jurídicas y Sociales, Facultad de Derecho y Ciencias Sociales, Universidad Nacional de Córdoba, pp. 443-459. Buenos Aires: La Ley.

Ciuffolini, M.A. (2010). Resistencias: Luchas sociales urbanas en Córdoba post-2001. Córdoba: EDUCC.

Ciuffolini, M.A. (2014). Un paradigma en construcción: interpretación, poder y subjetivación. En A. Núñez, M.A. Ciuffolini, et al. Tiempos itinerantes. Apropiación y expropiación de territorialidades sociales en ciudades argentinas, pp. 13-30. Mar del Plata: Eudem.

Fitoussi, J. y Rosanvallon, P. (2006). La nueva era de las desigualdades. Buenos Aires: Manantial. 
Foucault, M. (1992). Microfísica del poder. Madrid: La Piqueta.

Foucault, M. (2007). Seguridad, territorio, población. Buenos Aires: FCE.

Gautié, J. (2004). Repensar la articulación entre mercado de trabajo y protección social en el posfordismo. En Documentos para seminarios, 8. Buenos Aires: Ceil-Piette.

Giaretto, M. (2010). Las tomas de tierras urbanas y las posibilidades de una crisis del régimen de propiedad. En Universitas Humanística, 70, 133-149. Bogotá.

Giddens, A. (1994). Consecuencias de la modernidad. Madrid: Alianza.

Glaser, B. y Strauss, A. (1967). Discovery of Grounded Theory. Chicago: Aldine.

Gorz, A. (1980). Adiós al proletariado. Más allá del socialismo. Buenos Aires: Imago Mundi.

Gorz, A. (2003). Miserias del presente, riqueza de lo posible. Buenos Aires, Paidós.

Guadarrama, R. (2003). La cultura laboral. En E. De La Garza. Tratado Latinoamericano de Sociología del Trabajo. México: FCE.

Guattari, F. y Rolnik, S. (2013). Cartografías del deseo. Buenos Aires: Tinta Limón ediciones.

Guber, R. (2011). La etnografía. Método, campo y reflexividad. Buenos Aires: Siglo Veintiuno editores.

Holloway, J. (2004). Clase = Lucha. Antagonismo social y marxismo crítico. Buenos Aires: Herramienta.

Izaguirre, I. y Aristizábal, Z. (1988). Las tomas de tierras en la zona sur del Gran Buenos Aires. Un ejercicio de formación de poder en el campo popular. Buenos Aires: Centro Editor de América Latina.

Marín, J. (2009). Cuaderno 8. Buenos Aires: Ediciones PICASO - Colectivo Ediciones.

Negri, T. (2013). Los orígenes de la biopolítica. Un Seminario. En C. Altamira. Politica y subjetividad en tiempos de governance, pp. 151-176. Buenos Aires: Waldhuter.

Offe, C. (1992). La sociedad del trabajo. Problemas estructurales y perspectivas de futuro. Madrid: Alianza.

Offe, C. (1999). La abolición del control del mercado y el problema de la legitimidad. En H. Sonntag y H. Valencillos. El Estado en el capitalismo contemporáneo. México: Siglo Veintiuno editores. 
Oxman, C. (1998). La entrevista de investigación en Ciencias Sociales. Buenos Aires: Eudeba.

Ranciere, J. (2006). Política, policía, democracia. Santiago de Chile: Lom.

Ricoeur, P. (2001). Del texto a la acción. Buenos Aires: FCE.

Rosanvallón, P. (2004). La nueva cuestión social. Repensar el Estado providencia. Buenos Aires: Manantial.

Salas, C. (2000). El modelo de acumulación y el empleo en América Latina. En Enrique de la Garza (comp.): Reestructuración productiva, mercado de trabajo y sindicatos en América Latina. Buenos Aires: Clacso.

Soneira, A. (2007). La teoría fundamentada en los datos (Grounded theory) de Glaser y Strauss. En Vasilachis de Gialdino (coord.) Estrategias de investigación cualitativa, pp. 153-174. España: Gedisa.

Stratta, F. (2011). La disputa por el espacio urbano. Las tomas de tierra en el gran Buenos Aires durante los años ochenta. En Revista Herramienta, 48, octubre. Buenos Aires: Ediciones Herramienta.

Svampa, M. (2000). Desde abajo. La transformación de las identidades sociales. Buenos Aires: Biblos.

Virno, P. (2003). Gramática de la multitud. Buenos Aires: Colihue. 